\title{
Discussion on Application-oriented Curriculum Reform of Operating System Principle
}

\author{
Zhaogui Ma \\ Department of Information Science and Technology \\ Taishan College \\ Taian, China \\ mazhaogui1223@126.com
}

\begin{abstract}
Operating system principle is the core course of computer science, this paper analyzes the main problems existing in the teaching of operating system principle, such as the theoretical complexity of the course, the obsolescence of teaching content and the weakness of experiment. Aiming at the cultivation of applied talents, the application-oriented curriculum reform has been carried out from the aspects of curriculum concept, course content, teaching methods and practical teaching. The practice shows that the application-oriented teaching can promote students to better understand the theoretical knowledge, cultivate their thinking ability and hands-on ability, and ultimately promote their all-round development.
\end{abstract}

Keywords-Operating system; Curriculum reform; Application-oriented; Computer teaching

\section{INTRODUCTION}

The operating system is the first layer of software that is configured on the computer hardware and it is a set of programs that control and manage the hardware and software resources of the computer. All other system software and application software must depend on the operating system.

The course of operating system principle mainly introduces the working principle, design method, realization process and the related theories. It is a compulsory and professional course of computer science, and also is the postgraduate Entrance Examination course in many colleges and universities. It has a very important position in computer knowledge system [1]. The main purpose of the operating system principle course is to enable students to understand and master the basic principles of operating system, system structures and implementation methods, and tell them how to analyze and solve problems in software design and development.

In recent years, many colleges and universities in China have put forward the construction objectives for applied specialty and applied University, which requires that the teaching objects and course contents should be consistent with the industry requirement for talents [2]. Under this circumstance, according to the characteristics of the operating system principle course and the existing problems in the teaching process, we put forward the application-oriented curriculum reform ideas. By preparing a series of application cases, the theoretical knowledge can be incorporated into the case. In this way, teacher-student interaction can be realized, which will probably help to improve the effect of teaching.

\section{PRoblems In The TeAching OF OPERATING System PRINCIPLE}

\section{A. Course Content is Strong Theoretical and Obsolete}

The course content of operating system includes many topics, the knowledge points are mostly theoretical, and the concept is abstract. Many textbooks as well as the explanations rarely have actual applications. Students often feel that the curriculum is complicated [3]. At the same time, due to the rapid development of electronic technology, especially the continuous updating of chip technology, the performance of the computer is rapidly improved, which drives the function and performance of the operating system to be enhanced rapidly. In addition, the development of computer architecture has also been driving the operating system to generate new types. However, for a long time, the textbooks of operating system principle are difficult to keep up with the development of operating system technology, and are lack of integration with the frontier technology.

\section{B. The Involved Knowledge is Complex and Students Lack of Learning Interest and Motivation}

Other basic courses related to operating system principle involves principles of computer composition, system structure, data structure, advanced programming language and other hardware and software knowledge and technology. It is hard to understand so many courses deeply for students. In addition, due to their career planning, most students usually pay more attention to highly practical technologies, and don't like to learn theoretical courses, and finally lose their interests about this course. 


\section{Lack of Effective Teaching Methods}

At present, the teaching methods commonly used in domestic colleges and universities are mainly taught in the classroom, and it is a kind of "indoctrination" teaching method, focusing on teachers' teaching. Students think less, practice less, while heuristic and discussion-based teaching methods are rarely used.

\section{The Practice Teaching is Weak}

For a long time, the operating system experiments mainly include some demonstrative experiments, and the content of these experiments is old and boring, and the teaching time of experiment is less, and can't improve students' abilities.

\section{MEASURES OF APPLICATION-ORIENTED CURRICULUM REFORM}

\section{A. Change the Traditional Concepts and Establish the Engineering Teaching Concept}

Operating system principle involves more knowledge points and many difficulties. With the impact of school hours, teaching materials are generally an overview of the basic principles of the operating system, but lack of specific case analysis. Students can not understand the operating system clearly and flexibly use of relevant knowledge.

In recent years, the engineering education concept and implementation system(CDIO) advocated by MIT and the Royal Institute of Technology of Sweden have been widely popularized in higher engineering education schools [4]. CDIO represents conceive, design, implement and operate, which is the concentrated expression of "learning in practice" and "education and learning based on project", which can cultivate students' ability of engineering practice, comprehensive innovation ability and harmonious development with social environment.

In the teaching process of operating system principle, teachers can introduce the concept of engineering education, focus on combining specific cases to guide students in-depth understanding of the basic theory of operating systems. In the practice stage, we take the project as the center, improve the student's engineering practice ability. Through project-driven teaching, we can give guidance to students to help them find problems, analyze and solve them, and finally improve the students' self-learning and the innovation ability.

\section{B. Keep Abreast of Technical Frontier and Improve the Course Content}

TABLE I. MAIN TOPICS WITH OPERATING SYSTEM PRINCIPLE

\begin{tabular}{|l|l|}
\hline \multicolumn{1}{|c|}{ Core Chapters } & \multicolumn{1}{c|}{ Main Topics } \\
\hline Operating system overview & $\begin{array}{l}\text { The basic concepts, goals, functions, history and types of operating sys tems, and the } \\
\text { characteristics of modern operating systems }\end{array}$ \\
\hline The concept of the process & Discuss process control, process synchronization, process communication, and so on \\
\hline Processor scheduling and deadlock & $\begin{array}{l}\text { Introduce processor scheduling, threads, deadlock and other issues, focusing on scheduling } \\
\text { algorithm of first in first out, short job priority, time slice rotation algorithm }\end{array}$ \\
\hline Memory management & $\begin{array}{l}\text { Discusses a variety of storage management technologies, including continuous storage } \\
\text { technology, discrete storage technology, focusing on basic paging storage management and basic } \\
\text { segmented memory management }\end{array}$ \\
\hline Virtual memory & $\begin{array}{l}\text { Discuss request paging storage management, request segmented virtual storage technology, } \\
\text { focusing on hardware and software support for virtual storage technology }\end{array}$ \\
\hline File management & $\begin{array}{l}\text { Discuss the elements of file management, focusing on the logical structure of the file and the } \\
\text { physical structure, directory management }\end{array}$ \\
\hline Disk management & \begin{tabular}{l} 
Disk scheduling strategy and disk cache replacement algorithm \\
\hline Virtualization \\
the creation, deployment, and management of virtual machines
\end{tabular} \\
\hline
\end{tabular}

In 2013, ACM and IEEE prepared an undergraduate teaching reference programs for computer science. The plan is important and has a great impact on the undergraduate education of computer science. From the computer science curriculum system, we can find the development direction and goal of operating system teaching [5]. CS2013 draft emphasizes that the operating system defines an abstraction of hardware and manages resource sharing among the computer's users. The topics in this area explain the most basic knowledge of operating systems in the sense of interfacing an operating system to networks, teaching the difference between the kernel and user modes, and developing key approaches to operating system design and implementation. This knowledge area is structured to be complementary to Systems Fundamentals, Networks, Information Assurance, and the Parallel and Distributed Computing knowledge areas. The Systems Fundamentals and Information Assurance knowledge areas are the new 
ones to include contemporary issues. For example, the Systems Fundamentals includes topics such as performance, virtualization and isolation, and resource allocation and scheduling; Parallel and Distributed Systems knowledge area includes parallelism fundamentals; and Information Assurance includes forensics and security issues in depth. Many courses in Operating Systems will draw material from across these Knowledge Areas.

However, in recent years, computer technology has developed rapidly, especially with the rapid development of cloud computing and big data technology, IT companies have a strong demand for talents. Therefore, according to CS2013, we have optimized the operating system course content from the perspective of application-oriented personnel training, and adjusted the core chapters with following content of disk management, file management and virtualization technology. Table 1 shows the main chapters and points of operating system principle.

\section{Theory Combined with Reality and Carry Out Case Teaching}

The traditional teaching methods simply tell the students how to do it, but often ignore the practicality of the knowledge content itself, such that the students usually feel boring with the theoretical knowledge [6,7]. Through the real case, students may be granted more chances to think actively. Secondly, the traditional teaching method which only pursue content in the textbook, this will prevent the cultivation of students' ability. Case teaching method tends to cultivate students' practical ability. In the traditional teaching methods, teachers are the center of class, the students just listen to teachers. Examination is the only way to test students' learning outcomes. But case teaching pay more attention to students. When teachers begin to provide some case, the students will have a general understanding of the case. So students can learn from themselves, digest the knowledge involved in the case.

According to the current career direction of the students, the cases mainly cover the algorithm design ideas, program development skills, software debugging skills. For examples, we choose the case of "philosopher meal" for process synchronization, and case of "Segment fault" and "core dumped" for memory management.

\section{Strengthen the Experiment and Improve the Practical Ability}

Experiment is an important way to cultivate students' practical ability. To enable students to deeply understand and master the basic principles of the operating system, teachers must pay attention to the combination of theoretical teaching and experimental teaching. Teachers can develop students' programming ability and software design ability through experiments. If the measures of experimental teaching is too single, students will lose their interests. Therefore, all the experiments are divided into two parts: One part is the verification experiments, such as the process of creation and control, process synchronization, the process of communication mechanisms, page replacement and other typical experiments. These experiments can help students analysis and understand the basic principles of the operating system. The other part is curriculum design, including integrated and design experiments, which students can systematically understand the design and implementation method of the operating system. In these experiments, students can modify or rewrite operating system kernel.

In order to improve the experimental teaching effect, we built the OS Lab experimental platform [8],which is a small open source operating system EOS that can be run on X86 architecture. The source code of EOS is mainly written in C programming language, and the total source code does not exceed 10,000 lines. The experiment platform provides a visual IDE environment, so that students do not need to learn a variety of IDE environments.

\section{SUMMARY}

This paper analyzes the problems in the teaching of operating system principle. With the purpose of improving the quality of application talents, how to carry out the curriculum reform from teaching concept, course content, teaching methods and practice teaching are discussed. By changing the teaching concept, optimizing the course content, focusing on the combination of theory and practice, the students' interest can be fully stimulated and their abilities to analyze and solve problems can be improved.

\section{REFERENCES}

[1] X.D. Tang, H.B. Liang and F.P. Zhe, “Computer Operating System,” Xi' an University Press China, pp. 81-98, 2007.

[2] X.S. Cai, F.H. Yu and J.B. Dai, "The Application of Case Method on the Teaching of Operating System Principles," Journal of Changchun Normal University Vol. 34, pp. 123-125, 2015.

[3] Y. Ge, G.Z. Liu and J.W. Du, "The Multivariate Teaching Mode of Operating System Course," Computer Knowledge and Technology, Vol. 6, pp. 41954197, 2010.

[4] Y. Wang, Y.H. Zhang and L.J. Wei, "Discussion on teaching reform of operating system course based on CDIO idea," Computer Education, Vol. 22, pp. 111-114, 2016.

[5] Information on http://ai.stanford.edu/users/sahami/CS2013/strawman-draft/cs2013-strawman.pdf

[6] G.Z. Yi, "Research on Case Design for Practice Teaching of Operating System Course,” Journal of Xianyang Normal University, Vol. 29 , pp. 81-85, 2014.

[7] Q.Y. Zhang, “The application of problem-driven teaching method in college operating system,” Journal of Lvliang Education Institute, Vol. 29, pp. 95-96, 2012.

[8] Information on http://www.engintime.com/ 